\title{
Aa. Vv., Tristan Corbière, Dossier poètes maudits II, «Histoires littéraires», n. 33
}

Ida Merello

\section{(2) OpenEdition}

1 Journals

\section{Edizione digitale}

URL: http://journals.openedition.org/studifrancesi/8332

DOI: 10.4000/studifrancesi.8332

ISSN: 2427-5856

\section{Editore}

Rosenberg \& Sellier

\section{Edizione cartacea}

Data di pubblicazione: 1 mai 2009

Paginazione: 200

ISSN: 0039-2944

\section{Notizia bibliografica digitale}

Ida Merello, «Aa. Vv., Tristan Corbière, Dossier poètes maudits II, «Histoires littéraires», n. 33», Studi Francesi [Online], 157 (LIII | I) | 2009, online dal 30 novembre 2015, consultato il 12 janvier 2021. URL: http://journals.openedition.org/studifrancesi/8332 ; DOI: https://doi.org/10.4000/studifrancesi.8332

Questo documento è stato generato automaticamente il 12 janvier 2021.

\section{(c) (i) (9)}

Studi Francesi è distribuita con Licenza Creative Commons Attribuzione - Non commerciale - Non opere derivate 4.0 Internazionale. 


\title{
Aa. Vv., Tristan Corbière, Dossier poètes maudits II, «Histoires littéraires», n. 33
}

\author{
Ida Merello
}

\section{NOTIZIA}

Tristan Corbière, Dossier poètes maudits II, «Histoires littéraires», n. 33, janvier-mars 2008.

Benoît Houż̀ (Traces de Tristan Corbière: documents inédits ou retrouvés, pp. 13-34) ci offre qualche spigolatura: propone una lettera del poeta alla zia Christine Pujo che, oltre a confermare un'amitié amoureuse, offre preziose informazioni sul periodo di Roscoff e rivela un'abbondanza di riferimenti a testi in quel momento in gestazione o appena scritti. Si sofferma quindi sui disegni di pugno del poeta che accompagnano la sua copia delle Amours jaunes, per soffermarsi infine su un articolo di Armand Masson, uscito su «La Chronique parisienne» del 2 luglio 1882, precedente quindi quello di Verlaine che accoglie Corbière tra i maudits. Jean-Louis DEBAUVE presenta due lettere rispettivamente alla sorella e alla madre, samuel LAIR sedici indirizzate al padre Edouard, tratte dal carnet Scrapbook (che ne contiene quarantatré), con preziose indicazioni sul suo ruolo sociale. 